\title{
Severe Gonstrietion Band Syndrome of Digit in Neonate: Reduction with Z-Plasty
}

\section{JCR}

Sunraj Bangera

Department of Plastic and Reconstructive Surgery, A.J. Institute of Medical Sciences, Mangalore 575004, Karnataka, India.

\section{Abstract:}

Constriction band syndrome is a condition in which the cause of the constriction band is prematurely ruptured intrauterine strips of amniotic membrane circling around the extremities. Three day old female child presented with constriction band of the $3^{\text {rd }}$ and $4^{\text {th }}$ digits. Child had severe lymphoedema of the ring finger with constriction band at the level of proximal phalanx. The neonate underwent elliptical excision of the constriction bands over the dorsal aspect and Z-plasty of the ring and middle fingers. The lymphoedema reduced by $70 \%$ within a period of 6 months. Though surgical excision of excess skin is tempting, re-establishment of lymphatic circulation with Z-plasty does produce significant reduction. Redundant skin may be appropriately trimmed at a later date.

Key words: Constriction, Fingers, Infant, Lymphedema, Skin Diseases.

\section{Introduction}

Constriction band syndrome is a common condition occurring due to prematurely ruptured intrauterine strips of amniotic membrane circling around the extremities. Common complications of limb involvement in the amnion disruption sequence are: amputation, constriction rings, acrosyndactyly and lymphedema [1]. The amnion disruption sequence is known by other names, such as amniotic band syndrome, constriction ring syndrome, annular constriction rings and Streeter's dysplasia [2]. Congenital constriction band syndrome is a sporadic condition that may also be present in association with other congenital anomalies. We present a case of severe distal lymphoedema of digits regressed by $\mathrm{Z}$ plasty.

\section{Case Report}

Three day old neonate presented with constriction band of the right $3^{\text {rd }}$ and $4^{\text {th }}$ digits. Child had severe lymphedema of the ring finger with constriction band at the level of proximal phalanx. There was severe ballooning of the ring finger with loss of length of the ring finger. There was complete absence of the middle and distal phalanx of the ring finger. There was minimal movement at the metacarpophalangeal joint due

\section{Corresponding Author: Dr. Sunraj Bangera}

Email: sunraj_bangera@yahoo.co.in

Received: June 3, 2016 | Accepted: September 17, 2016 | Published Online: October 30, 2016

This is an Open Access article distributed under the terms of the Creative Commons Attribution License (creativecommons.org/licenses/by/3.0)

Conflict of interest: None declared | Source of funding: Nil | DOl: http://dx.doi.org/10.17659/01.2016.0124 
to the enormous swelling. The circumference of the $4^{\text {th }}$ digit was $9 \mathrm{cms}$. In the middle finger the constriction bands were at the level of the proximal and middle phalanges. The length of the middle finger was normal and in proportion to the index and little fingers. Movements of the middle finger were normal and unrestricted by the constriction bands. The thumb, index finger and little finger were normal in appearance and had normal movements. The digits of the left hand and both feet were normal. There was no evidence of any other associated congenital anomalies. Child had birth weight of $3.5 \mathrm{kgs}$. As it was a neonate, radiograph of the right hand was avoided to prevent the adverse effects of radiation exposure. Routine blood investigations were carried out to attain clearance for anesthesia. Early intervention became mandatory to salvage the affected fingers. Parents were anxious about the large size of the digit.

Surgical options were excision of the groove around the fingers, dorsal Z plasty and trimming of the excessive skin of the ring finger. The neonate underwent elliptical excision of the groove over the dorsal aspect and Z-plasty of the ring and middle fingers. Excision of the excess skin was considered, but not performed to evaluate the outcome of Z-plasty postoperatively [3]. Utilization of the dorsal Z-plasty enabled establishment of lymphatic continuity resulting in resolution of lymphoedema of the ring and middle fingers. The lymphoedema reduced by $70 \%$ within a period of 6 months. Further resolution of the lympoedema is expected followed by utilization of phalanx transfer from the toe to support the soft tissue of the ring finger.

\section{Discussion}

The lymphedema and growth impairment distal to the groove results from circulatory compromise due to compression caused by constriction rings.

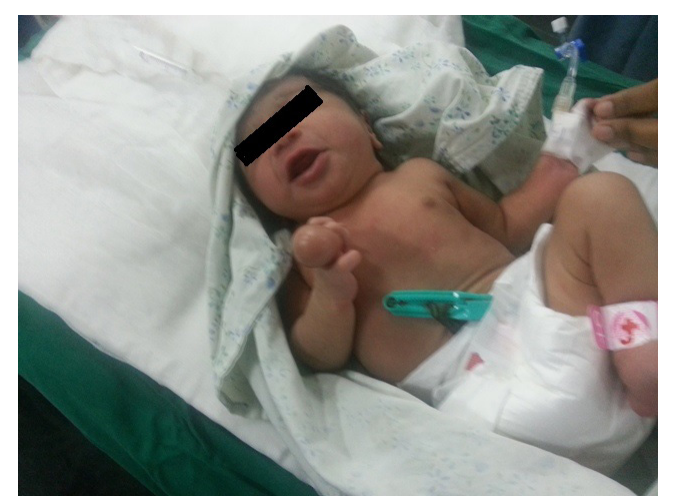

Fig. 1: Severe lymphedema of the ring finger.

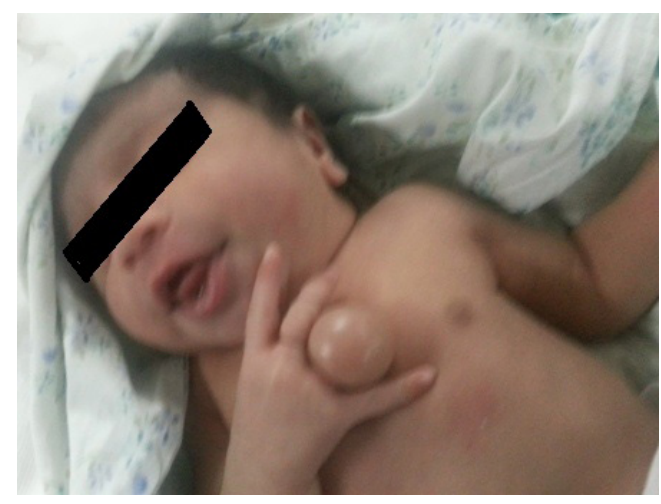

Fig.2: Constriction ring syndrome.

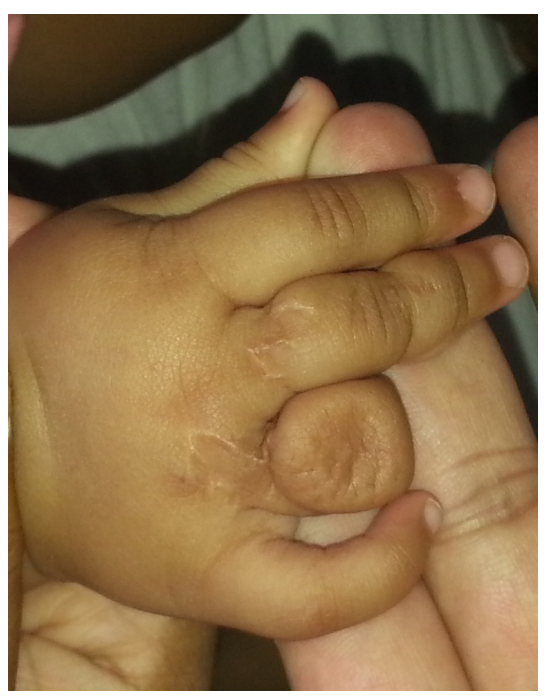

Fig.3: Z-plasty of ring and middle fingers. 
Amniotic band syndrome, or amniotic disruption complex, is seen in 1200 to one in 15,000 live births. Risk factors include oligohydramnios, prematurity, maternal illness, low birth weight and drug exposure. Congenital constriction band syndrome is a sporadic condition that may also be present in association with other congenital anomalies.

Congenital constriction band syndrome not only causes aesthetic deformity in the affected limb, but may also cause vascular compromise, which can lead to lymphedema and amputation. Our three day old neonate presented with constriction band of the right $3^{\text {rd }}$ and $4^{\text {th }}$ digits. Child had severe lymphoedema of the ring finger with constriction band at the level of proximal phalanx. There was severe ballooning of the ring finger with loss of length of the ring finger. There was complete absence of the middle and distal phalanx of the ring finger. There was minimal movement at the metacarpophalangeal joint due to the enormous swelling. In the middle finger the constriction bands were at the level of the proximal and middle phalanges. The length of the middle finger was normal and in proportion to the index and little fingers. Early intervention became mandatory to salvage the affected fingers. Parents were anxious about the large size of the digit. Oligohydramnios results in abnormal pressure on the fetal distal extremities and intrauterine amputations may occur due to disruption of in-utero limb circulation. Generally little finger and the thumb are affected less frequently $[4,5]$. The massive swelling distal to the constriction causes anxiety among parents and early intervention is necessary. The primary aim is to preserve vascularity and reduce distal edema.

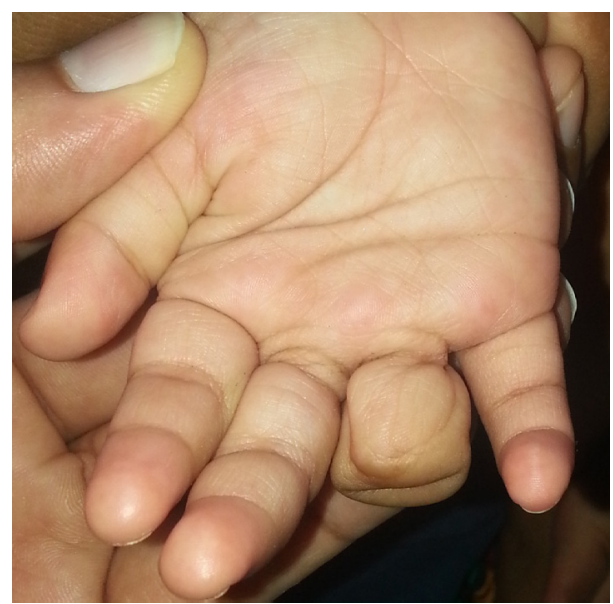

Fig.4: Reduction of lymphedema.

\section{Conclusion}

Though surgical excision of excess skin is tempting, re-establishment of lymphatic circulation with Z-plasty does produce significant reduction. Redundant skin may be appropriately trimmed at later date. The syndrome and its complications are amenable to corrective surgery with good results. Early intervention is desirable for a successful outcome.

\section{References}

1. Patterson TJS. Congenital ring constrictions. Br J Plast Surg. 1961;14:1-31

2. Streeter GL. Focal deficiencies in fetal tissues and their relation to intra-uterine amputation. Contrib Embryol. 1930;1:22.

3. Stevenson TW. Release of circular constricting scars by $z$ flaps. Plast Reconstr Surg. 1946;1:39-42.

4. Ogino T, Saitou Y. Congenital constriction band syndrome and transverse deficiency. I Hand Surg. 1987;1 2B:343-348.

5. Narang $M$, Nidhi, Dhanewa A. Streeter's dysplasia. Journal of Case Reports. $2011 ; 1$ :1617. 